\title{
A Study of Insulin Resistance by HOMA-IR and its Cut-off Value to Identify Metabolic Syndrome in Urban Indian Adolescents
}

\author{
Yashpal Singh1, MK Garg1, Nikhil Tandon2, Raman Kumar Marwaha3 \\ 1 Command Hospital (Southern Command), Department of Endocrinology, Pune, India \\ 2 All Indian Institute of Medical Sciences, Department of Endocrinology, New Delhi, India \\ 3 International Life Sciences, Scientific Advisor (Projects), New Delhi, India
}

\begin{abstract}
Objective: Insulin resistance (IR) and associated metabolic abnormalities are increasingly being reported in the adolescent population. Cut-off value of homeostasis model of assessment IR (HOMA-IR) as an indicator of metabolic syndrome (MS) in adolescents has not been established. This study aimed to investigate IR by HOMA-IR in urban Indian adolescents and to establish cut-off values of HOMA-IR for defining MS.

Methods: A total of 691 apparently healthy adolescents (295 with normal body mass index (BMI), 205 overweight, and 199 obese) were included in this cross-sectional study. MS in adolescents was defined by International Diabetes Federation (IDF) and Adult Treatment Panel III (ATP III) criteria. IR was calculated using the HOMA model.

Results: Mean height, waist circumference (WC), waist/hip ratio (WHR) waist/height ratio (WHtR), and blood pressure were significantly higher in boys as compared to girls. The HOMA-IR values increased progressively from normal weight to obese adolescents in both sexes. Mean HOMA-IR values increased progressively according to sexual maturity rating in both sexes. HOMA-IR value of 2.5 had a sensitivity of $>70 \%$ and specificity of $>60 \%$ for MS. This cut-off identified larger number of adolescents with MS in different BMI categories (19.7\% in normal weight, $51.7 \%$ in overweight, and $77.0 \%$ in obese subjects) as compared to the use of IDF or ATP III criteria for diagnosing MS. Odds ratio for having IR (HOMA-IR of $>2.5$ ) was highest with WHtR (4.9, $p<0.0001)$ and $W C(4.8, p<0.0001)$, compared to WHR $(3.3, p<0.0001)$.

Conclusions: In Indian adolescents, HOMA-IR increased with sexual maturity and with progression from normal to obese. A HOMA-IR cut-off of 2.5 provided the maximum sensitivity and specificity in diagnosing MS in both genders as per ATP III and IDF criteria.
\end{abstract}

Key words: Insulin resistance, metabolic syndrome, HOMA-IR, adolescents

Conflict of interest: None declared

Received: 25.06 .2013

Accepted: 24.10 .2013

\section{Introduction}

Insulin resistance (IR) and the metabolic abnormalities related to IR have been associated with metabolic syndrome (MS), type 2 diabetes mellitus (T2DM) and cardiovascular disease (CVD) in adults and in the elderly. MS is now increasingly being recognized in children and adolescents $(1,2)$. Childhood obesity which is increasing worldwide is well known for its association with IR (3).

IR is typically defined as decreased sensitivity or responsiveness to the metabolic actions of insulin, such as insulin-mediated glucose disposal and inhibition of hepatic glucose production. There are various tools used for quantifying insulin sensitivity and resistance directly (hyperinsulinemic euglycemic glucose clamping and insulin suppression tests) and indirectly [frequently sampled intravenous glucose tolerance test, oral glucose tolerance test, meal tolerance test, and homeostasis model of assessment-IR (HOMA)] (4). The utility of HOMA-IR in assessment of IR has been validated in children and adolescents $(5,6)$. A HOMA-IR value of 2.5 is taken as an indicator of IR in adults (7), but the corresponding value in children and adolescents has not been established. Studies evaluating HOMA-IR in obese children and adolescents are few $(5,8,9,10,11,12,13,14)$. Of these, a limited number are population-based studies, and the remaining are studies conducted on small samples. It is well known that the frequency of IR varies in the two sexes and among different ethnic groups. Since there are no studies from India identifying the cut-off levels for HOMA-IR in the adolescent population, we undertook this study to evaluate IR by HOMA-IR in Indian

Address for Correspondence

Raman Kumar Marwaha MD, International Life Sciences, Scientific Advisor (Projects), New Delhi, India

Phone: +919810296820 E-mail: marwaha_ramank@hotmail.com

(C) Journal of Clinical Research in Pediatric Endocrinology, Published by Galenos Publishing. 
adolescents according to sexual maturation rating (SMR) and body mass index (BMI) categories and to establish cut-off values of HOMA-IR as an indicator of IR.

\section{Methods}

The subjects of a previously conducted survey in schools located in four different geographical zones of Delhi constituted the source from which the sample was selected (15). Nine hundred adolescents (300 each in obese, overweight and normal weight categories) in the age group 10-17 years were selected by computerized random number generation and were invited to take part in the study. A total of 691 apparently healthy adolescents consented to participate, and the group included 199 obese, 205 overweight, and 295 normal weight adolescents, as defined by the International Obesity Task Force criteria (16). These subjects underwent a detailed clinical, biochemical and hormonal evaluation and were found to be free of any systemic illness.

The study was conducted according to the guidelines laid down in the Declaration of Helsinki, and all procedures involving human subjects/patients were approved by the Institutional Human Ethics Committee of Institute of Nuclear Medicine and Allied Sciences, Timarpur, Delhi. Written informed consent was obtained from all subjects/patients. A prior consent for the study was taken from the school administration and from the parents. At the time of initiating the study, parents of each participant provided written informed consent for their ward's participation. Assent from children was also obtained before drawing blood samples.

Height was measured to the nearest $0.1 \mathrm{~cm}$ using a stadiometer (a portable wall-mounted stadiometer $(200 \mathrm{~cm} / 78$ inches) model DS045 manufactured by Narang Medical Ltd. Delhi) with the subject in the erect position, with his/her head held in Frankfurt horizontal plane. Weight was measured to the nearest $0.1 \mathrm{~kg}$, without shoes and wearing light clothes, using an electronic digital weighing machine (EQINOX - Model EB6171, Equinox Overseas Private Limited, New Delhi). Height and weight measurements were taken twice, and the mean of two measurements was used to calculate BMI. Waist circumference (WC) was measured midway between the superior border of the iliac crest and the lowermost margin of the ribs at the end of normal expiration. Hip circumference was measured around the point with the maximum circumference over the buttocks, with feet fairly close together (about 12-15 $\mathrm{cm}$ apart) and weight equally distributed on each leg. Blood pressure was measured according to method described by the Seventh Report of the Joint National Committee (17).

The adolescents were given written instructions to fast for 12 hours, and compliance was assessed by interviewing the subjects and their parent(s) on the morning of the test. For the oral glucose tolerance test, the glucose load was calculated as $1.75 \mathrm{~g} / \mathrm{kg}$ to a maximum of $75 \mathrm{~g}$. Air tight packets of calculated glucose load were prepared for each child on the day prior to the test. After a 12-hour overnight fast, venous blood samples were drawn, and the participants were given the glucose load. Two-hour post-load samples were taken for determination of plasma glucose and serum insulin. During the interim period, the children were kept in the fasting state in the examination hall and did not indulge in any strenuous physical activity. Fasting and post-load plasma glucose levels were estimated on the same day and the remaining aliquots were stored at $-20^{\circ} \mathrm{C}$ until assayed.

The glucose oxidase-peroxidase method was used for measurements of plasma glucose (Clonital, Italy). Fasting serum total cholesterol, high-density lipoprotein (HDL) cholesterol, and triglycerides (TG) were estimated using an automated analyzer (Hitachi-902 fully automated biochemistry analyzer; Roche, Manheim, Germany) and commercial kits (Roche, Manheim, Germany). Serum insulin level was measured using commercial kits and an electrochemiluminiscence device (Elicsys, Roche Diagnostics), with a measurement range of 3.5-2083.5 pmol/L and a given normal value of 14.6-152.8 pmol/L. Intra-assay and inter-assay coefficients of variation were $4.3 \%$ and $3.4 \%$, respectively. IR was calculated by using the HOMA model [HOMA-IR = fasting insulin $(\mu \mathrm{l} \mathrm{U} / \mathrm{mL}){ }^{*}$ fasting glucose $(\mathrm{mmol} / \mathrm{L}) / 22.5]$ (4).

BMI was defined as the ratio of body weight to body height squared, expressed in $\mathrm{kg} / \mathrm{m}^{2}$. WC cut-offs as proposed by Kuriyan et al (17) were used to identify children with a WC $>90^{\text {th }}$ centile (18). Waist/hip ratio (WHR) and waist/height ratio (WHtR) were calculated, and a WHR ratio of 0.9 in boys and 0.8 in girls (19) was taken as a cut-off for WHR and a WHtR of 0.5 (20) as a cut-off for WHtR. Using these cut off values, the subjects were divided into two groups. Hypertension was defined as a systolic (SBP)/diastolic blood pressure (DBP) greater than 90th centile for age and sex (21). SMR was determined by Tanner \& White method $(22,23)$

MS in adolescents was defined by the International Diabetes Federation (IDF) criteria (24) [WC $>90^{\text {th }}$ percentile with any two of the parameters ( $T G \geq 1.69 \mathrm{mmol} / \mathrm{L}, \mathrm{HDL}$ $<1.03 \mathrm{mmol} / \mathrm{L}, \mathrm{FPG}>5.6 \mathrm{mmol} / \mathrm{L}$, and $\mathrm{BP}>130 / 85 \mathrm{mmHg}$ ] and Adult Treatment Panel III (ATP III) criteria (25) [abnormality in any of three parameters, namely $W C>90^{\text {th }}$ percentile, dysglycemia, hypertension ( $>95^{\text {th }}$ percentile for SBP or DBP), hypertriglyceridemia ( $>95^{\text {th }}$ percentile), and low HDL $\left(<5^{\text {th }}\right.$ percentile)]. Any degree of dysglycemia was defined by impaired fasting glucose (IFG) - fasting plasma glucose $>100$ $125 \mathrm{mg} / \mathrm{dL}$ (>5.6-6.9 mmol/L), impaired glucose tolerance (IGT) - 2-hour post 75 glucose load plasma glucose 141-199 mg/ $\mathrm{dL}(7.8-11.0 \mathrm{mmol} / \mathrm{L})$ and $\mathrm{DM}$ - fasting plasma glucose $\geq 126$ $\mathrm{mg} / \mathrm{dL}$ ( $\geq 7.0 \mathrm{mmol} / \mathrm{L}$ ) or post glucose plasma glucose $\geq 200$ $\mathrm{mg} / \mathrm{dL}(\geq 11.1 \mathrm{mmol} / \mathrm{L})$ as per the definition provided by the 
American Diabetic Association (26). Recently, our group has published reference range for lipid profile in Indian adolescents in the age group 10-18 years, where the 95th percentile for TG in adolescents is above the adult limit of $150 \mathrm{mg} / \mathrm{dL}$ and the $5^{\text {th }}$ percentile value for $\mathrm{HDL}$ is lower than $40 \mathrm{mg} / \mathrm{dL}(<1.03$ $\mathrm{mmol} / \mathrm{L})(27)$. Hence, we have taken adult cut-off points in MSATP definition, which are that $\geq 1.69 \mathrm{mmol} / \mathrm{L}$ for $\mathrm{TG}$, and $<1.03$ $\mathrm{mmol} / \mathrm{L}$ for $\mathrm{HDL}$.

The SPSS version 20.0 (SPSS Inc. Chicago, USA) was used for the statistical analyses. The data are presented as mean \pm standard deviation or number $(\%)$, unless specified otherwise. All parametric data were analyzed by the independent student's t-test in categorical groups. All nonparametric data were analyzed by chi-square test. Pearson's correlation coefficient was calculated to assess the strength of relationship between lipid HOMA-IR and other parametric variables. Receiver operator characteristic $(\mathrm{ROC})$ curves were plotted using HOMA-IR and presence or absence of metabolic abnormalities. Youden's index was calculated by sensitivity (1-specificity), obtained from co-ordinates of the curve. Highest value for Youden's index was used to identify the cut-off value of HOMA-IR. A p-value of $<0.05$ was considered statistically significant.

\section{Results}

The basic characteristics of the study population are depicted in Table 1. The mean HOMA-IR of the study population was $2.83 \pm 2.05$ (Boys: $2.77 \pm 1.98$, Girls: $2.93 \pm 2.11$ ). HOMA-IR showed no consistent pattern in relation to age and sex, showed the lowest value at age 13 years, then increased significantly to reach a peak at 17 years (Table 2).

The HOMA-IR values increased progressively from normal weight to obese (Figure 1) in both sexes. Boys: normal weight $1.70 \pm 1.44(95 \% \mathrm{Cl} 1.46-1.94)$ vs. overweight $2.67 \pm 1.41$ $(95 \% \mathrm{Cl} 2.40-2.94)$ vs. obese $4.39 \pm 2.14(95 \% \mathrm{Cl} 3.95-4.83)$, p-value $<0.0001$ between all groups); Girls: normal weight $1.21 \pm 1.10(95 \% \mathrm{Cl} 1.73-2.12)$ vs. overweight $3.19 \pm 2.02(95 \%$ $\mathrm{Cl}$ 2.79-3.60) vs. obese $4.19 \pm 2.52$ (95\% Cl 3.69-4.69), p-value $<0.0001$ between all groups). The mean values of HOMA-IR were comparable among adolescent boys and girls as a group $(p=0.78$ ) and when divided according to BMl categories (Normal weight $p=0.966$; Overweight $p=0.061$; Obese $p=0.168$ ).

The mean HOMA-IR values progressively increased with increasing sexual maturation. There were $96(13.8 \%)$ prepubertal (mean age 11.5 \pm 1.0 , range 10-14 years) and 248 post- pubertal boys (mean age $13.7 \pm 1.8$, range $10-17$ years).

\begin{tabular}{|c|c|c|c|}
\hline Parameters & Boys $(n=344)$ & Girls $(n=347)$ & p-value \\
\hline Age (years) & $13.3 \pm 1.9$ & $13.46 \pm 1.9$ & 0.15 \\
\hline Height (cm) & $157.1 \pm 12.4$ & $152.7 \pm 8.6$ & $<0.00001$ \\
\hline Weight $(\mathrm{kg})$ & $57.6 \pm 19.6$ & $56.5 \pm 17.2$ & 0.6331 \\
\hline BMI $\left(\mathrm{kg} / \mathrm{m}^{2}\right)$ & $22.81 \pm 5.64$ & $23.86 \pm 5.87$ & 0.016 \\
\hline$W C(\mathrm{~cm})$ & $78.2 \pm 16.4$ & $71.6 \pm 13.0$ & $<0.00001$ \\
\hline WHR & $0.88 \pm 0.06$ & $0.79 \pm 0.06$ & 0.008 \\
\hline WHtR & $0.50 \pm 0.09$ & $0.47 \pm 0.07$ & $<0.0001$ \\
\hline $\mathrm{SBP}(\mathrm{mmHg})$ & $113.4 \pm 12.1$ & $110.5 \pm 11.2$ & 0.001 \\
\hline $\mathrm{DBP}(\mathrm{mmHg})$ & $75.6 \pm 8.4$ & $73.8 \pm 7.5$ & 0.006 \\
\hline $\mathrm{TG}(\mathrm{mmol} / \mathrm{L})$ & $1.51 \pm 0.63(1.44)^{*}$ & $1.60 \pm 0.55(1.58)^{*}$ & 0.008 \\
\hline Total cholesterol (mmol/L) & $4.81 \pm 1.21(4.55)^{*}$ & $4.91 \pm 1.22(4.63)^{*}$ & 0.25 \\
\hline HDL cholesterol (mmol/L) & $1.14 \pm 0.19$ & $1.14 \pm 0.20$ & 0.72 \\
\hline LDL cholesterol (mmol/L) & $2.98 \pm 1.11(2.75)^{*}$ & $3.03 \pm 1.14(2.78)^{*}$ & 0.52 \\
\hline Fasting plasma glucose (mmol/L) & $5.08 \pm 0.50$ & $5.03 \pm 0.52$ & 0.25 \\
\hline 2-hour plasma glucose (mmol/L) & $5.61 \pm 1.06$ & $5.64 \pm 0.99$ & 0.69 \\
\hline Fasting insulin (pmol/L) & $82.64 \pm 56.94$ & $89.72 \pm 60.42$ & 0.73 \\
\hline HOMA-IR & $2.77 \pm 1.98$ & $2.93 \pm 2.11$ & 0.78 \\
\hline
\end{tabular}


HOMA-IR values were significantly higher in post-pubertal boys (2.92 \pm 2.08$)$ compared to pre-pubertal boys $(2.26 \pm 1.72$, $\mathrm{p}=0.003$ ). There was no significant difference in HOMA-IR values between pubertal stages 1-3. A significant difference in mean HOMA-IR values was observed between Tanner stages 1-2 and stages 4-5, in both boys and girls. The peak HOMA-IR values were reached at Tanner stage 5 in both sexes (Table 3).

The prevalence of $\mathrm{MS}$ in normal $\mathrm{BMI}$, overweight, and obese adolescents was $1 \%, 18.4 \%$, and $49 \%$ ( $p<0.00001)$, respectively, using the modified ATP III criteria and $0.3 \%$, $13.6 \%$, and $46.4 \%(p<0.00001)$, respectively, using the IDF definition. The HOMA-IR cut-off value for MS was determined by ROC curve. Although the HOMA-IR value of 2.0 showed maximum sensitivity for diagnosing MS as defined by IDF $(86.3 \%)$ and ATP $(85.1 \%)$, it had low specificity $(46.4 \%$ and $47.7 \%$, respectively). A sensitivity of $>70 \%$ and specificity of $>60 \%$ was indicated by HOMA-IR value of 2.5 (Table 4). According to this cut-off, the number of adolescents with IR in different BMI categories would be $58(19.7 \%)$ in normal weight, $106(51.7 \%)$ in overweight, and $147(77.0 \%)$ in obese groups, respectively. When both techniques (definition of MS by IDF or HOMA-IR cut-off of 2.5) were combined, the yields for MS were higher: 59 (20.0\%), 121 (58.7\%), and 172 $(90.0 \%)$ in normal, overweight, and obese group, respectively. Adolescents with any component of MS had significantly higher HOMA-IR values than those without (Table 4).

HOMA-IR was positively correlated with the majority of anthropometric and biochemical parameters (Table 5). The odds ratio for having IR (HOMA-IR of $>2.5$ ) was greater with high WHtR [4.9 (95\% Cl 3.6-6.8, p<0.0001)] and WC [4.8 (95\% $\mathrm{Cl} 3.5-6.7, \mathrm{p}<0.0001)]$ compared to WHR [3.3 (95\% Cl 2.4-4.8, $\mathrm{p}<0.0001)]$.

Table 2. Homeostasis model of assessment insulin resistance (HOMA-IR) according to age in both sexes

\begin{tabular}{|c|c|c|c|c|c|c|c|}
\hline \multirow{2}{*}{$\begin{array}{l}\text { Age } \\
\text { (years) }\end{array}$} & \multicolumn{2}{|c|}{ Numbers } & \multicolumn{2}{|c|}{ Mean HOMA-IR (SD) } & \multicolumn{2}{|c|}{ 95\% Confidence limits } & \multirow[t]{2}{*}{ p-value } \\
\hline & Boys & Girls & Boys & Girls & Boys & Girls & \\
\hline 10 & 17 & 19 & $2.74(1.12)$ & $2.91(1.57)$ & 2.17-3.33 & $2.10-3.60$ & \multirow[t]{2}{*}{0.018 (Boys) } \\
\hline 11 & 52 & 44 & $2.55(1.93)$ & $2.59(1.73)$ & 2.01-3.09 & $2.09-3.12$ & \\
\hline 12 & 60 & 58 & $2.34(1.63)$ & $2.83(2.20)$ & $1.92-2.76$ & $2.25-3.41$ & \multirow{7}{*}{0.709 (Girls) } \\
\hline 13 & 60 & 58 & $2.19(1.53)$ & $3.00(2.03)$ & $1.79-2.59$ & $2.40-3.50$ & \\
\hline 14 & 70 & 48 & $2.85(2.05)$ & $3.29(2.29)$ & $2.36-3.34$ & $2.45-3.78$ & \\
\hline 15 & 30 & 52 & $3.45(2.71)$ & $2.62(1.69)$ & $2.43-4.40$ & $2.14-3.09$ & \\
\hline 16 & 40 & 61 & $3.22(2.05)$ & $3.52(2.43)$ & $2.56-3.88$ & $2.60-3.80$ & \\
\hline 17 & 15 & 7 & $3.60(2.72)$ & $3.41(3.87)$ & $2.09-5.11$ & $-1.71-6.9$ & \\
\hline Total & 344 & 347 & $2.72(1.98)$ & $3.01(2.25)$ & $2.51-2.93$ & $2.70-3.25$ & \\
\hline
\end{tabular}

p-values between age groups in boys: (10 yrs vs. all ages: NS; $11-15$ years: $0.047 ; 12-15$ years: $0.012 ; 12-16$ years: $0.027 ; 12-17$ years: $0.026 ; 13-15$ years: $0.004 ; 13-16$ years: 0.010 ; 13-17 years: 0.013 ; 14- All ages: NS. p-values between age groups in all age groups were NS

NS: not significant, SD: standard deviation

Table 3. Homeostasis model of assessment insulin resistance (HOMA-IR) mean values by stages of pubertal development

\begin{tabular}{|c|c|c|c|c|c|c|c|}
\hline \multirow{2}{*}{$\begin{array}{l}\text { Tanner } \\
\text { stage }\end{array}$} & \multicolumn{2}{|c|}{ Numbers } & \multicolumn{2}{|c|}{ Mean HOMA-IR (SD) } & \multicolumn{2}{|c|}{ 95\% Confidence limits } & \multirow{2}{*}{ p-value } \\
\hline & Boys & Girls & Boys & Girls & Boys & Girls & \\
\hline 1 & 96 & & $2.26(1.75)$ & & $1.91-2.60$ & & \multirow{5}{*}{$\begin{array}{l}<0.0001 \text { (Boys) } \\
<0.0001 \text { (Girls) }\end{array}$} \\
\hline 2 & 64 & 67 & $2.45(1.74)$ & $1.88(1.02)$ & $2.01-2.89$ & $1.63-2.13$ & \\
\hline 3 & 54 & 63 & $2.42(1.55)$ & $2.65(1.30)$ & $2.0-2.84$ & $2.3-2.98$ & \\
\hline 4 & 66 & 71 & $3.11(2.28)$ & $3.01(2.24)$ & $2.55-3.67$ & $2.48-3.54$ & \\
\hline 5 & 64 & 146 & $3.56(2.25)$ & $3.49(2.48)$ & 2.9-4.12 & $3.08-3.89$ & \\
\hline
\end{tabular}


Table 4. Homeostasis model of assessment insulin resistance (HOMA-IR) by various metabolic syndrome (MS) parameters

\begin{tabular}{|llll|}
\hline Parameter & Present & Absent & p-value \\
$\uparrow W C$ & $3.72 \pm 2.13$ & $2.25 \pm 1.76$ & $<0.0001$ \\
Hypertension & $3.55 \pm 2.38$ & $2.38 \pm 1.67$ & $<0.0001$ \\
$\uparrow$ Total cholesterol & $3.12 \pm 1.93$ & $2.72 \pm 2.08$ & 0.308 \\
$\uparrow$ TG & $3.52 \pm 1.95$ & $2.42 \pm 1.99$ & 0.029 \\
$\downarrow$ HDL & $3.05 \pm 2.21$ & $2.57 \pm 1.99$ & 0.010 \\
Dysglycemia & $4.55 \pm 2.79$ & $2.57 \pm 1.77$ & $<0.0001$ \\
MS-IDF & $4.14 \pm 2.31$ & $2.47 \pm 1.81$ & $<0.0001$ \\
MS-ATP & $4.11 \pm 2.35$ & $2.43 \pm 1.79$ & $<0.0001$ \\
\hline WC: waist circumference, TG: triglyceride, HDL: high-density lipoprotein, \\
IDF: International Diabetes Federation, ATP: Adult Treatment Panel \\
\hline \multicolumn{4}{|l}{} \\
\hline
\end{tabular}

Table 5. Correlation of various parameters with homeostasis model of assessment insulin resistance (HOMA-IR)

\begin{tabular}{|lll|}
\hline Parameter & r-value & p-value \\
\hline Age (years) & 0.113 & 0.003 \\
Height (cm) & 0.274 & $<0.0001$ \\
Weight (Kg) & 0.532 & $<0.0001$ \\
BMI (kg/m²) & 0.549 & $<0.0001$ \\
WC (cm) & 0.514 & $<0.0001$ \\
WHR & 0.233 & $<0.0001$ \\
WHtR & 0.487 & $<0.0001$ \\
DBP (mmHg) & 0.304 & $<0.0001$ \\
SBP (mmHg) & 0.392 & $<0.0001$ \\
Fasting plasma glucose (mg/dL) & 0.350 & $<0.0001$ \\
Post-load plasma glucose (mg/dL) & 0.187 & $<0.0001$ \\
TG (mg/dL) & 0.297 & $<0.0001$ \\
HDL (mg/dL) & -0.017 & 0.659 \\
Total cholesterol (mg/dL) & 0.107 & 0.005 \\
\hline BMI: body mass index, WC: waist circumference, WHR: waist/hip ratio, & \\
WHtR: waist/height ratio, DBP: diastolic blood pressure, SBP: systolic blood pressure, \\
TG: triglyceride, HDL: high-density lipoprotein \\
\hline
\end{tabular}

\section{Discussion}

The increase in incidence and prevalence of T2DM and its cardiovascular complications is probably a consequence of the global epidemic of obesity. The rising prevalence of obesity in the Indian child and adolescent population is a cause of concern $(28,29,30)$ as it not only predisposes to adult obesity but also increases the likelihood of negative health consequences (31). Commensurate with the rising trend of adolescent obesity is the rising prevalence of $\mathrm{IR}$ and $\mathrm{MS}$ in

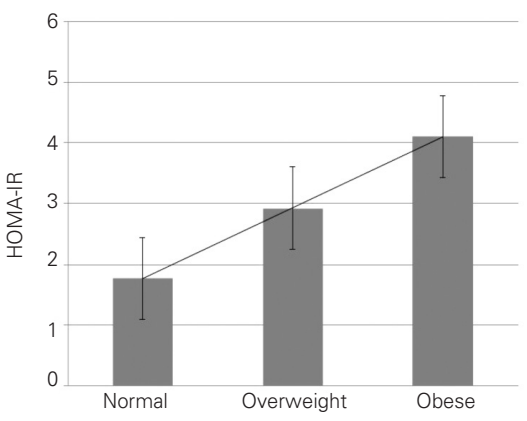

Figure 1. Homeostasis model of assessment insulin resistance (HOMA-IR) according to body mass index (BMI) categories

this population $(32,33,34,35)$. Several studies from different populations were conducted to establish HOMA-IR cut-off values for MS in adolescents $(5,6,13,14)$. At present, however, there are no data defining the cut-off values of HOMA-IR for Indian adolescents. A study from the southern part of India demonstrated a correlation between HOMA-IR and glucose intolerance (36). This present study is the first large scale work which analyzed HOMA-IR values in obese, overweight, and normal weight adolescents in both sexes, also taking into account age, pubertal status, and metabolic abnormalities associated with MS.

In our study, the mean HOMA-IR values showed inconsistent pattern according to age with no significant difference among girls in different age groups in contrast to boys, who showed lowest levels at 13 years and peak HOMAIR values at 17 years of age. A study among healthy children from Spain showed a progressive rise in HOMA-IR with age for both boys and girls (37). The Early Bird Diabetes study from UK had prospectively evaluated HOMA-IR in healthy children aged 5-14 years (9) and found IR to start rising from mid-childhood ( 7 years), a few years before puberty. The present study comprising adolescents between 10-17 years, being crosssectional in design, may have missed an early rise of IR, which may have stabilized after pre-pubertal years. Also, lack of a correlation of HOMA-IR with age may possibly be related to the heterogeneity of pubertal status in the same chronological age groups, especially among girls.

In this study, as expected, both boys and girls showed a progressive increase in mean HOMA-IR values with increasing BMI. A significant difference among the HOMA-IR values of normal weight, overweight, and obese adolescents was observed. High values for HOMA-IR in obese subjects compared to normal adolescents [Mean HOMA-IR: 4.93 (95\% Cl 4.56-5.35) vs. 2.30 (2.21-2.39), respectively], has also been validated in a large study among adolescents from USA (8).

There is no consensus on HOMA-IR cut-off values for identifying MS in adolescents. In the current study, a HOMAIR cut-off of 2.5 provided adequate sensitivity and specificity 
in diagnosing MS in both boys and girls as per ATP III and IDF criteria. There are no previous studies from India which have tried to establish HOMA-IR cut-offs to identify MS in this subset of population. HOMA-IR values ranging from 2.22 to 3.16 have been reported as cut-off for identifying IR in various studies $(5,12,13,38)$, but all these studies were conducted on small samples of obese children and adolescents and hence, are likely to report higher cut-off values. The cut-off values derived in our study are more likely to be applicable as they have been derived from a large cohort with a homogenous mix of normal-weight, overweight, and obese adolescents.

IR has been implicated in causation of MS; this may imply that metabolic abnormalities associated with MS are the end result of long-term IR (38). This is further reiterated by the results of the present study, where HOMA-IR cut-off identified a large number of normal-weight and overweight adolescents with IR who otherwise would have been missed by the IDF and ATP III criteria. A similar observation was made by a study from Turkey (13). These children may be at risk of future development of MS. This assumes significance for children and adolescents from the Indian subcontinent, since these populations were found to be more insulin resistant than their Caucasian counterparts (39). This is further substantiated by our study, where $77 \%$ of obese adolescents had IR compared to about $52 \%$ in a study among US adolescents (8). Hence, intervention in the group of adolescents with underlying IR without metabolic abnormalities may prevent development of MS. However, this strategy requires validation in future studies.

In this study, HOMA-IR showed significant correlations with $\mathrm{BMI}, \mathrm{WC}$ and $\mathrm{WH} t \mathrm{R}$, while the correlation between WHR and HOMA-IR was poor. Other studies including one from India (35) also observed the strongest correlation of HOMA-IR with WC $(35,40,41,42)$. Another parameter which has shown good correlation with HOMA-IR in our study is WHtR. A similar result was reported in a large study from Europe (43). All these studies have shown that WC and WHtR are good predictors of $\mathrm{IR}$ in adolescents and can be used to identify at risk individuals. Amongst the various biochemical parameters, elevated TG was correlated with HOMA-IR, whereas HDL did not show a significant correlation. HOMA-IR was significantly higher in those adolescents who were positive for components of MS.

The strength of our study is the large number of adolescents in the sample with comparable distribution in all $\mathrm{BMI}$ categories. Its limitation is absence of Iongitudinal followup.

In conclusion, this study has shown that HOMA-IR is a valuable tool in identifying adolescents with MS. A HOMA-IR cut-off of 2.5 provided the maximum sensitivity and specificity in diagnosing MS in both genders as per ATP III and IDF criteria. This cut-off value may also serve to identify adolescents at high risk of future MS and who are amenable to early intervention. Among anthropometric parameters, WC and WHtR are the two anthropometric parameters that correlated best with IR.

\section{Acknowledgement}

We are thankful to Dr Namita Mahalle, Department of Pathology, Deenanath Mangeshkar Hospital and Research Centre, Erandawane, Pune for providing help in statistical analysis.

\section{References}

1. Invitti C, Guzzaloni G, Gilardini L, Morabito F, Viberti G. Prevalence and concomitants of glucose intolerance in European obese children and adolescents. Diabetes Care 2003;26:118- 124.

2. Ten $\mathrm{S}$, Maclaren $\mathrm{N}$. Insulin resistance syndrome in children. J Clin Endocrinol Metab 2004;89:2526- 2539.

3. Gupta N, Goel K, Shah P, Misra A. Childhood obesity in developing countries: epidemiology, determinants, and prevention. Endocr Rev 2012;33:48-70. Epub 2012 Jan 12

4. Matthews DR, Hosker JP, Rudenski AS, Naylor BA, Treacher DF, Turner RC. Homeostasis model assessment: insulin resistance and beta-cell function from fasting plasma glucose and insulin concentrations in man. Diabetologia 1985;28:412-419.

5. Atabek ME, Pirgon O. Assessment of insulin sensitivity from measurements in fasting state and during an oral glucose tolerance test in obese children. J Pediatr Endocrinol Metab 2007;20:187-195.

6. Keskin M, Kurtoglu S, Kendirci M, Atabek ME, Yazici C. Homeostasis model assessment is more reliable than the fasting glucose/insulin ratio and quantitative insulin sensitivity check index for assessing insulin resistance among obese children and adolescents. Pediatrics 2005;115:500-503. Epub 2005 Mar 1

7. Muniyappa R, Lee S, Chen H, Quon MJ. Current approaches for assessing insulin sensitivity and resistance in vivo: advantages, limitations, and appropriate usage. Am J Physiol Endocrinol Metab 2008;294:15-26. Epub 2007 Oct 23

8. Lee JM, Okumura MJ, Davis MM, Herman WH, Gurney JG. Prevalence and determinants of insulin resistance among U.S. adolescents: a population-based study. Diabetes Care 2006;29:2427-2432.

9. Jeffery AN, Metcalf BS, Hosking J, Streeter AJ, Voss LD, Wilkin TJ.Age before stage: insulin resistance rises before the onset of puberty: a 9-year longitudinal study (EarlyBird 26). Diabetes Care 2012;35:536-541. Epub 2012 Jan 25

10. Pilia S, Casini MR, Foschini ML, Minerba L, Musiu MC, Marras $V$, Civolani P, Loche S. The effect of puberty on insulin resistance in obese children. J Endocrinol Invest 2009;32:401-405.

11. Burrows RA, Leiva LB, Weisstaub G, Lera LM, Albala CB, Blanco E, Gahagan S. High HOMA-IR, adjusted for puberty, relates to the metabolic syndrome in overweight and obese Chilean youths. Pediatr Diabetes 2011;12:212-218. Epub 2011 Mar 22

12. lamopas $\mathrm{O}$, Chongviriyaphan N, Suthutvoravut U. Metabolic syndrome in obese Thai children and adolescents. J Med Assoc Thai 2011;94(Suppl 3):126-132.

13. Kurtoglu S, Hatipoglu N, Mazicioglu M, Kendirici M, Keskin M, Kondolot M. Insulin Resistance in Obese Children and Adolescents: HOMA IR Cut Off Levels in the Prepubertal and Pubertal Periods. J Clin Res Pediatr Endocrinol 2010;2:100-106. Epub 2010 Aug 2

14. Kurtoglu S, Akin L, Kendirci M, Hatipoglu N, Elmali F, Mazicioglu $M$. The absence of insulin resistance in metabolic syndrome definition leads to underdiagnosing of metabolic risk in obese patients. Eur J Pediatr 2012;171:1331-1337. Epub 2012 Mar 28 
15. Tandon N, Garg MK, Singh Y, Marwaha RK. Prevalence of metabolic syndrome in urban Indian adolescents and its relation with insulin resistance (HOMA-IR). J Pediatr Endocrinol Metab 2013:1-8. Epub ahead of print

16. Cole TJ, Bellizzi MC, Flegal KM, Dietz WH. Establishing a standard definition for child overweight and obesity worldwide: international survey. BMJ 2000;320:1240-1243.

17. Kuriyan R, Thomas T, Lokesh DP, Sheth NR, Mahendra A, Joy R, Sumithra S, Bhat S, Kurpad AV. Waist circumference and waist for height percentiles in urban South Indian children aged 3-16 years. Indian Pediatr 2011;48:765-771. Epub 2011 Mar 15

18. Misra A, Vikram NK, Gupta R, Pandey RM, Wasir JS, Gupta VP. Waist circumference cut-off points and action levels for Asian Indians for identification of abdominal obesity. Int J Obes (Lond) 2006:30:106-111.

19. Ashwell M, Hsieh SD. Six reasons why the waist-to-height ratio is a rapid and effective global indicator for health risks of obesity and how its use could simplify the international public health message on obesity. Int J Food Sci and Nutr 2005;56:303-307.

20. The Seventh Report of the Joint National Committee on Prevention, Detection, Evaluation, and Treatment of High Blood Pressure (JNC-7). Hypertension 2003:42:1206.

21. National High Blood Pressure Education Program Working Group on High Blood Pressure in Children and Adolescents. The fourth report on the diagnosis, evaluation, and treatment of high blood pressure in children and adolescents. Pediatrics 2004;114(Suppl 4):555-576.

22. Marshall WA, Tanner JM. Variations in pattern of pubertal changes in girls. Arch Dis Child 1969;44:291-303.

23. Marshall WA, Tanner JM. Variations in pattern of pubertal changes in boys. Arch Dis Child 1970;45:13-23.

24. Zimmet P. The IDF consensus definition of the Metabolic Syndrome in Children and Adolescents. www.idf.org/webdata/ docs/Mets definition children.pdf (assessed on 23 Jun 2013).

25. Third report of the National Cholesterol Education Program Expert Panel on Detection, Evaluation and Treatment of High Blood Cholesterol in Adults (Adult Treatment Panel III). Bethesda, Md.: National Heart, Lung, and Blood Institute, May 2001 (NIH publication no. 01-3670.)

26. American Diabetes Association. Standards of Medical Care in Diabetes-2012. Diabetes Care 2012;35:11-61.

27. Marwaha RK, Khadgawat R, Tandon N, Kanwar R, Narang A Sastry A, Bhadra K. Reference interval of lipid profile in healthy school children and adolescents. Clin Biochem 2011:44:760 766. Epub 2011 May 19

28. Gupta N, Shah P, Nayyar S, Misra A. Childhood Obesity and the Metabolic Syndrome in Developing Countries. Indian J Pediatr 2013;80(Suppl 1):28-37. Epub 2013 Jan 20

29. Misra A, Shah P, Goel K, Hazra DK, Gupta R, Seth P Tallikoti $P_{\text {, }}$ Mohan I, Bhargava R, Bajaj S, Madan J, Gulati S, Bhardwaj S, Sharma R, Gupta N, Pandey RM. The high burden of obesity and abdominal obesity in urban Indian schoolchildren: a multicentric study of 38,296 children. Ann Nutr Metab 2011;58:203-211. Epub 2011 Jul 14

30. Marwaha RK, Tandon N, Singh Y, Aggarwal R, Grewal K, Mani K. A Study of Growth Parameters and Prevalence of Overweight and Obesity in School Children from Delhi. Indian Pediatr 2006:43:943-952

31. Whitaker RC, Wright JA, Pepe MS, Seidel KD, Dietz WH. Predicting obesity in young adulthood from childhood and parental obesity. N Engl J Med 1997;37:869-873.
32. Singh R, Bhansali A, Sialy R, Aggarwal A. Prevalence of metabolic syndrome in adolescents from a north Indian population. Diabet Med 2007;24:195-199.

33. Yatheesha BL, Borade A, Rajam L. Metabolic Syndrome in the at risk for overweight and overweight children and adolescents. Pediatric Oncall 2010, available online at http:// www.pediatriconcall.com/fordoctor/Medical_original_articles/ metabolic.asp

34. Vikram NK, Misra A, Pandey RM, Luthra K, Wasir JS, Dhingra V. Heterogeneous phenotypes of insulin resistance and its implications for defining metabolic syndrome in Asian Indian adolescents. Atherosclerosis 2006; 186:193-199. Epub 2005 Aug 26

35. Misra A, Vikram NK, Arya S, Pandey RM, Dhingra V, Chatterjee A, Dwivedi M, Sharma R, Luthra K, Guleria R, Talwar KK. High prevalence of insulin resistance in postpubertal Asian Indian children is associated with adverse truncal body fat patterning, abdominal adiposity and excess body fat. Int $\mathrm{J}$ Obes Relat Metab Disord 2004;28:1217-1226.

36. Ranjani H, Sonya J, Anjana RM, Mohan V. Prevalence of Glucose Intolerance Among Children and Adolescents in Urban South India (ORANGE-2). Diabetes Technol Ther 2013;15:13-19. Epub 2012 Nov 14

37. García Cuartero B, García Lacalle C, Jiménez Lobo C, González Vergaz A, Calvo Rey C, Alcázar Villar MJ, Díaz Martínez E. The HOMA and QUICKI indexes, and insulin and C-peptide levels in healthy children. Cut off points to identify metabolic syndrome in healthy children. An Pediatr (Barc) 2007;66:481-490.

38. Morrison JA, Glueck CJ, Horn PS, Schreiber GB, Wang P. Homeostasis model assessment of insulin resistance*body mass index interactions at ages 9 to 10 years predict metabolic syndrome risk factor aggregate score at ages 18 to 19 years: a 10 -year prospective study of black and white girls. Metabolism 2009;58:290-295.

39. Lakshmi S, Metcalf B, Joglekar C, Yajnik CS, Fall CH, Wilkin TJ. Differences in body composition and metabolic status between white U.K. and Asian Indian children (Early Bird 24 and the Pune Maternal Nutrition Study). Pediatr Obes 2012;7:347-354. Epub 2012 Aug 31

40. Wedin WK, Diaz-Gimenez L, Convit AJ. Prediction of insulin resistance with anthropometric measures: lessons from a large adolescent population. Diabetes Metab Syndr Obes 2012;5:219225. Epub 2012 Jul 23

41. Hirschler V, Aranda C, Calcagno Mde L, Maccalini G, Jadzinsky M. Can waist circumference identify children with the metabolic syndrome? Arch Pediatr Adolesc Med 2005;159:740-744.

42. Bitsori $M$, Linardakis $M$, Tabakaki $M$, Kafatos $A$. Waist circumference as a screening tool for the identification of adolescents with the metabolic syndrome phenotype. Int J Pediatr Obes 2009;4:325-331.

43. Kondaki K, Grammatikaki E, Pavón DJ, Manios Y, GonzálezGross M, Sjöstrom M, Gottrand F, Molnar D, Moreno LA, Kafatos A, Gilbert C, Kersting M, De Henauw S. Comparison of several anthropometric indices with insulin resistance proxy measures among European adolescents: The Helena Study. Eur J Pediatr 2011;170:731-739. Epub 2010 Oct 30 